\title{
Serviceability of Suction Caisson Founded Offshore Structures
}

\author{
James A Cox ${ }^{1}$ and Subhamoy Bhattacharya ${ }^{2}$ \\ ${ }^{1}$ Assistant Geotechnical Engineer, WS Atkins, Bristol \\ ${ }^{2}$ Professor, Department of Civil and Environmental Engineering, University of Surrey
}

\begin{abstract}
Suction caissons have recently been considered as a cost effective alternative to conventional foundations for offshore met-masts and wind turbines. Such foundation arrangements are suitable for applications within water depths of 20-30m. Most offshore structures have stringent serviceability limit states imposed on their design dictating the allowable structural deflections and accumulated rotations throughout its operational life. This paper summarises the findings from a series of scale model tests and identifies key factors which influence the serviceability performance of a caisson founded offshore structure. These tests were conducted using representative caisson models in loose sand under single-g conditions, replicating a fully drained prototype condition. These experiments recorded the rotational foundation stiffness (soil structure interaction), the evolution of foundation stiffness under cyclic loading and the accumulation of structural rotation with loading cycles. It was discovered that the foundation stiffness was dependent on the local soil strain, and under cyclic loading would increase in a logarithmic manner. In addition it was found that under cyclic loading, a caisson system will retain and accumulate structural rotation following with a power relationship. From these observations it was possible to produce an analytical model and describe the changing serviceability state of a prototype structure with loading cycles.
\end{abstract}

\section{Keywords}

Foundations, Geotechnical engineering, Offshore Engineering 


\section{Notation}

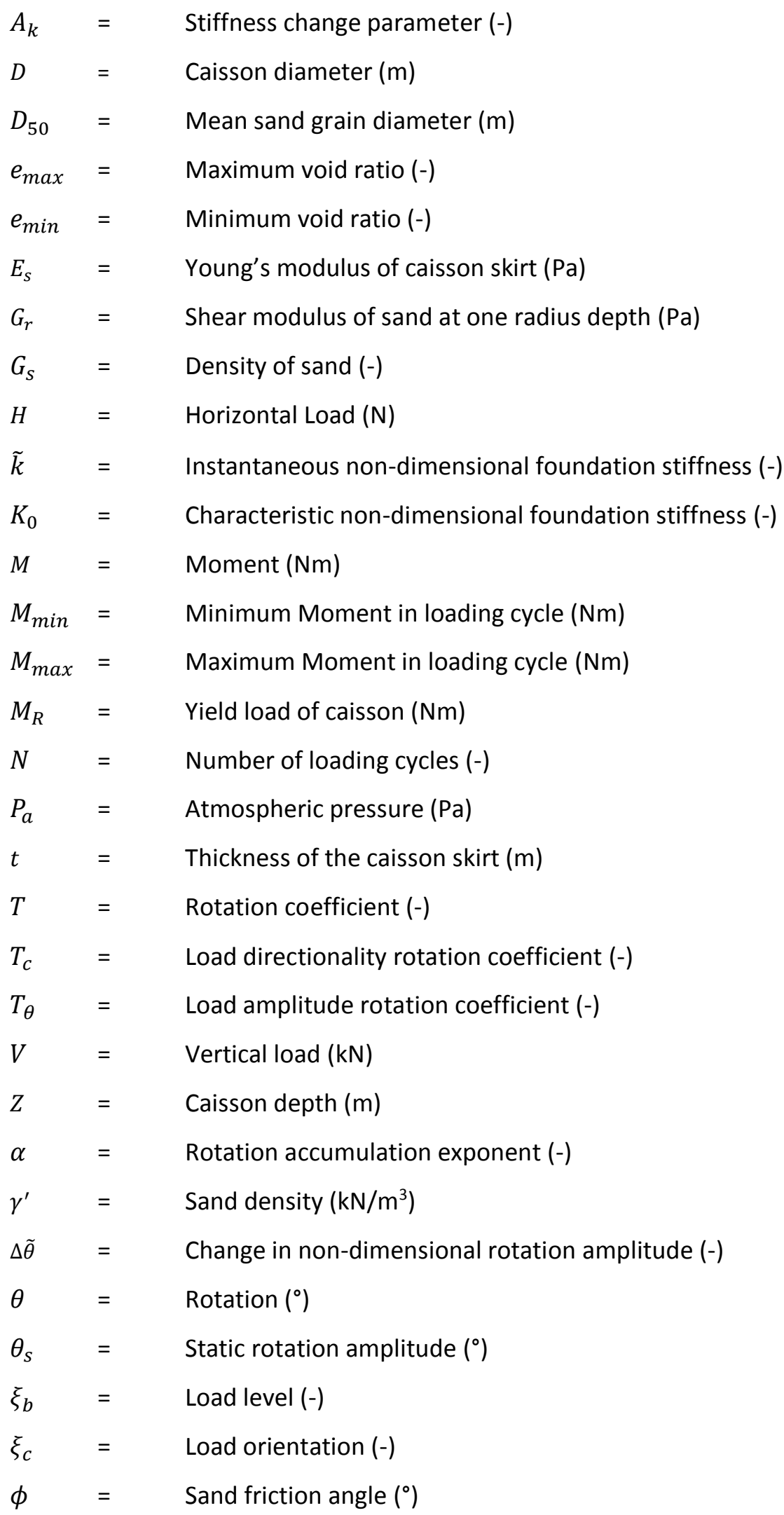




\section{Introduction}

Around $80 \%$ of all operational offshore wind turbines are founded on a single large diameter pile referred to commonly as a monopile (European Wind Energy Association, 2016). Monopile foundations are expensive due to the pile driving equipment and support vessels needed to achieve installation. As the cost of foundations currently make up around $20 \%$ of an offshore wind project (Larsen et al., 2005; Carter, 2007; DTI, 2007), there is a desire to develop an economical alternative to piled foundations, one alternative is the suction caisson.

A suction caisson is a shallow foundation enhanced by a perimeter skirt taking the form of an upturned steel bucket. This is installed into the seabed using suction provided by a pump; as such installation requires less equipment and creates less noise than a piled foundation. Caissons have been widely used by the offshore oil and gas industry, for tension leg platforms, jacket and jack-up structures (Andersen et al., 2005). Caissons have however only been applied to a few dynamically sensitive structures, such as wind turbines (Liingaard, 2006) and met masts (LeBlanc, 2009b).

Wind turbines have a number of serviceability limits states imposed upon them dictating the total structural rotation, maximum deflection and modal frequencies. These limits are specified in order to avoid placing additional stresses on the mechanical components of the turbine. In the case of the Thornton Bank wind park the structural rotation was limited to $0.25^{\circ}$ (Peire et al., 2009) and the modal frequencies were required to be $10 \%$ different to that of any periodic load (Det Norske Veritas, 2002). From a design perspective, any change in foundation stiffness during long-term cyclic loading will cause causing the first modal frequency of the system to shift, potentially instigating unwanted dynamic interactions. An example of the dynamic loads applied to an offshore turbine and the dynamic design solutions are illustrated in Figure 11.
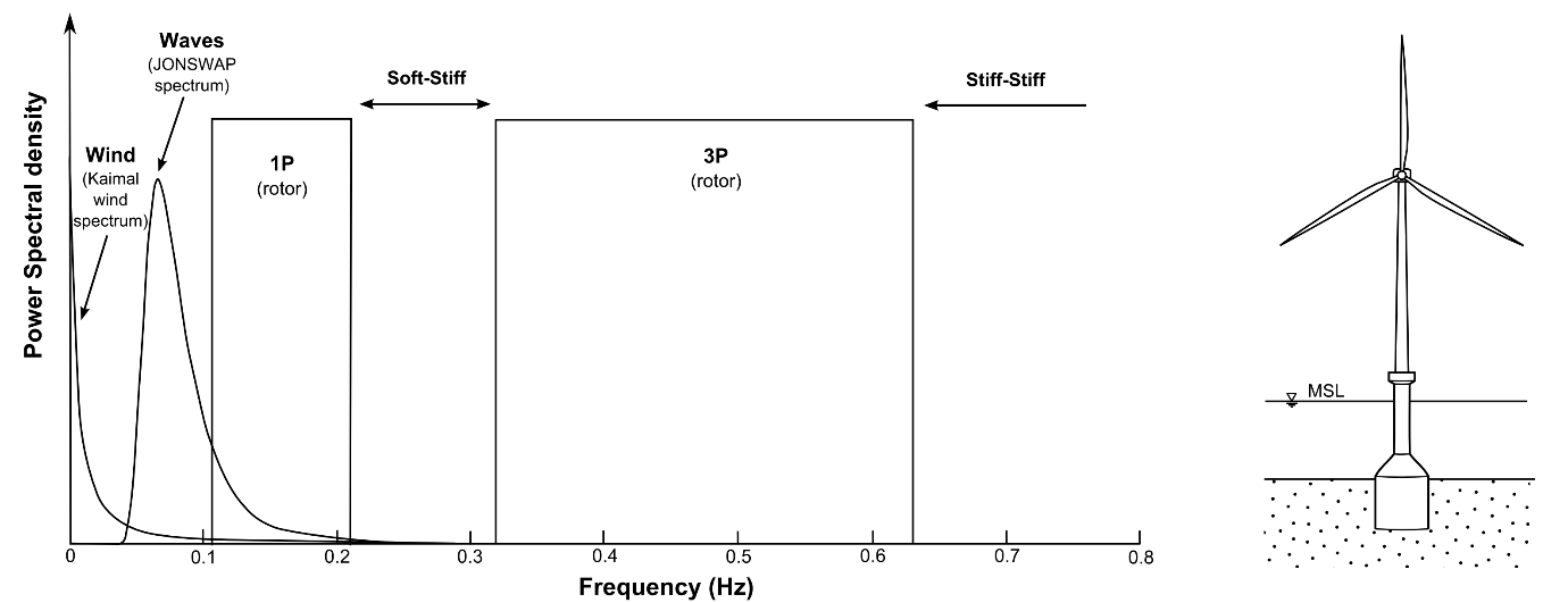

Figure 1: Typical cyclic loads and dynamically sensitive regions of a NREL 5MW turbine structure (Cox et al., 2015).

Offshore wind turbines are very modern structures, the first offshore turbine was constructed in 1991, with large scale projects being deveolped in the early 2000s (Zaaijer, 2009), accordingly there is little operational data concerning their long-term serviceability performance. To date a significant amount of research has been conducted into the serviceability of offshore foundations. The main focus of research has been into monopile foundations (LeBlanc et al., 2010a; Bhattacharya et al., 2012). More recently research has considered suction caissons focusing on scaled testing, modelling the monotonic caisson response (Feld, 2001; Houlsby et al., 2005; Villalobos, 2006), and the behaviour of a caisson subjected to a cyclic load (Byrne, 2000; Villalobos, 2006; Zhu et al., 2013). These tests have however 
only considered the response of the caisson in isolation and for a limited number of cycles; as such the long-term serviceability performance is not well understood.

The aim of this paper is to identify and predict the transient serviceability behaviour of a cyclically loaded caisson foundation. This investigation will utilise scale model testing with caissons of varying aspect ratios. The aim being to assess the changing serviceability considerations with continued cyclic loading.

\section{Similitude relationships}

In order to correctly model and interpret the data extracted from scale model testing, a number of similitude relationships were required. These relationships allow for factors that influence the behaviour of the system to be evaluated at a common scale and compared in the same terms. One way this can be achieved is through non-dimensional groupings, the groups utilised in this investigation are summarised in Table 1.

These groups define the relative flexibility of the caisson skirt (group 1), the soil stress (groups 2-4), the caisson aspect ratio (group 5) the soil strain properties (group 6) and the ratio of moment to horizontal load (group 7). The derivation and explanation of the groups have been covered in more detail elsewhere (Cox, 2014). These groups have been successfully employed in the analysis of a series of cyclic centrifuge tests conducted on suction caissons (Cox et al., 2015).

To date a limited number of dynamically sensitive offshore structures (wind turbines and met masts) have been founded on suction caissons. These are the Frederikshavn wind turbine (Liingaard, 2006), the Qidong Sea pre-stressed concrete caisson (Zhang et al., 2014), the Wilhelmshaven offshore wind turbine (LeBlanc, 2009b), the Horns Rev 2 and Dogger bank met masts (LeBlanc, 2009a). The characteristic non-dimensional scaling values for these structures were evaluated and summarised in Table 1. Utilising additional groupings it was possible to non-dimensionalise the system behaviour, allowing the experimental results to be evaluated and compared to other investigations. The nondimensional groupings suggested by Kelly et al., (2006), and presented in Table 2, will be utilised.

\section{Testing Program}

Within this investigation a series of caissons were utilised to assess the long-term serviceability performance. In total 2 caisson designs were considered, designated B2 and B3 with a diameter of $150 \mathrm{~mm}$ and an aspect ratio (D/Z) of 1 and 2 respectively. Tests were conducted at a scale of 1:100 under single-g conditions to replicate the prototype structures (as summarised in Table 1).

The models were designed to exhibit similar behaviour to the prototype structures as captured in the non-dimensional groups. The caisson flexibility (Group 1) had a target value of 10, estimating the sand shear modulus at a depth of D/2 (Hardin and Drnevich, 1972), the caissons were manufactured from acrylic (Young's modulus, Es $=3 \mathrm{GPa}$ ) to maintain similitude. The model weight was also tailored such that the dimensionless vertical capacity (Group 3) was within the prototype range. Considering a typical sand unit weight, $\gamma^{\prime}=15 \mathrm{kN} / \mathrm{m}^{3}$, a strain multiplier (Group 6) of 3778-5173 was achieved. This was above that desired; however such a value is typical of tests conducted under single-g conditions where the relative stress-strain properties of the sand are not maintained (Gaudin et al., 2010; Cox et al., 2015).

All tests were carried out using a long-stroke actuator instrumented with a load cell and a potentiometer. This apparatus was designed to apply a horizontal cyclic load to the model caisson system at an eccentric height. The connection between the actuator and the model was made using a flexible loading bar effectively creating a pinned connection to the model, allowing free rotation and displacement of the structure. A schematic of the test apparatus can be seen in Figure 12. 


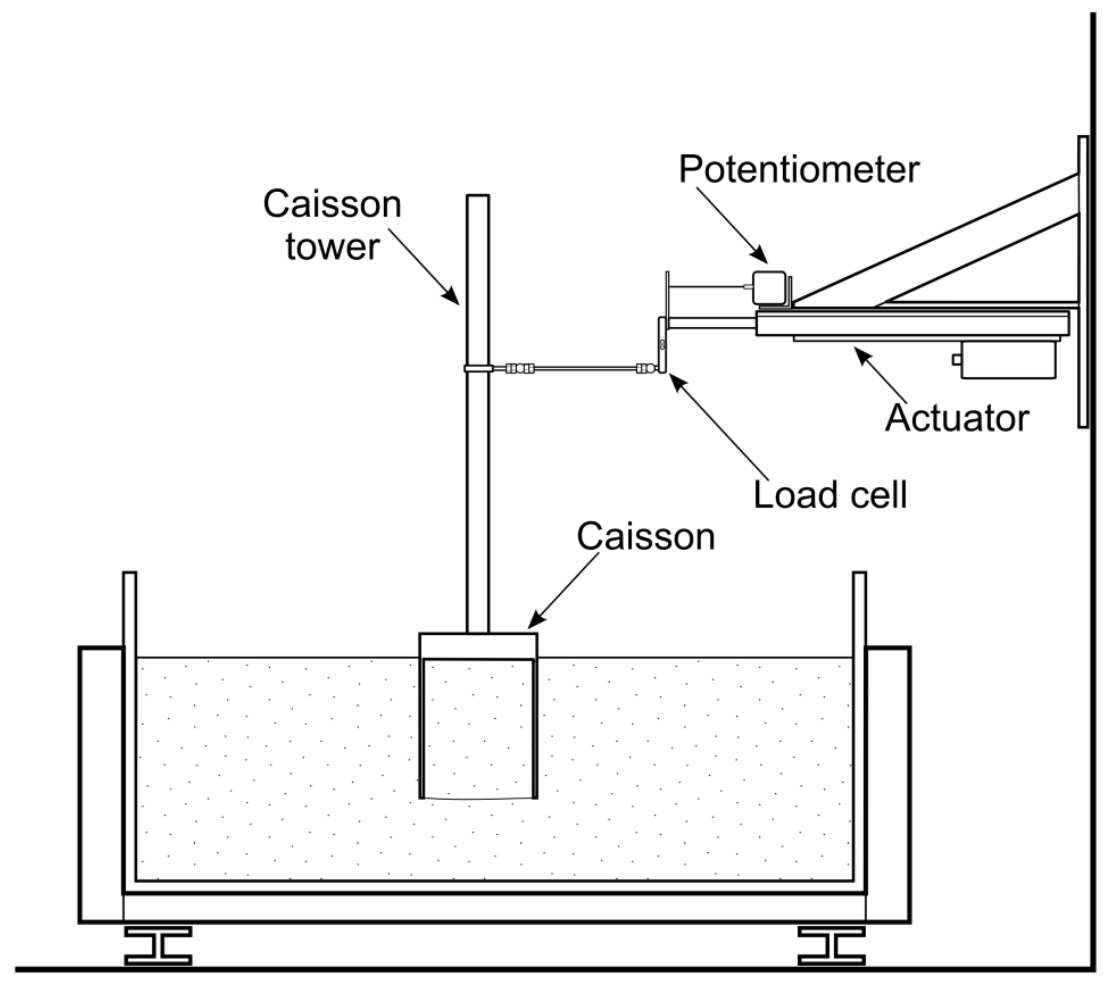

Figure 2: Schematic of the cyclic loading apparatus after Cox, (2014).

For all tests a known mass of sand was placed within a ridged container, consisting of a $968 \mathrm{~mm}$ long x $950 \mathrm{~mm}$ wide $\times 350 \mathrm{~mm}$, plywood box reinforced with a steel frame. This box was filled with a loose sample of Leighton Buzzard Fraction B sand using a spot pluviation apparatus (Moccia., 2009). Leighton Buzzard Fraction B is very uniform course silica sand that has been widely used within research; the properties of this sand can be found in Table 3. Volumetric measurements provided an estimation of the sand unit weight, yielding an average of $15.0 \mathrm{kN} / \mathrm{m}^{3},\left(D_{r}=25 \%\right)$.

As the mean particle size $\left(D_{50}\right)$ to foundation diameter ratio (D) was greater than 60 (Hoadley et al., 1981) particle size effects did not need to be considered. A minimum edge to edge clearance of 2 diameters between adjacent test locations and the ridged boundary was provided to prevent any unwanted interaction effects. Throughout the sand remained dry replicating a fully drained offshore condition. By considering the radial consolidation solution proposed by Randolph and Wroth, (1979), it can be estimated that for a range of typical loading frequencies and permeabilities, a prototype foundation will exhibit predominantly drained behaviour.

For each test the following experimental procedure was adopted:

1. A sand sample was created using a spot pluviation apparatus.

2. The model caisson was push installed into an undisturbed region of sand, (ensuring sufficient clearance between the model and the boundary), until the soil plug contacted the caisson soffit. Verticality was maintained with the use of an inclinometer. Installing the foundation under single-g conditions causes the sand displaced during installation to dilate and heave more in comparison to a prototype case (Tran, 2005). As only the transient behaviour was of interest, the installation was not modelled. 
3. The embedment of the caisson was then measured and the actuator moved to the correct elevation to apply the required loading.

4. The actuator was then attached to the turbine tower using a flexible connection.

5. Using a Simulink program the desired loading regime was specified, then enabled to apply a load to the structure.

6. The load and corresponding displacement of the system were recorded throughout the experimental period.

7. Once the test had been completed the loading was ceased, the actuator disconnected and the caisson removed from the sand.

Within the investigation two loading regimes were applied to the model system, these are detailed as follows:

- Push over tests [P]: This allowed the quasi-static rotational caisson stiffness to be estimated. By displacing the model tower at an eccentric height, the applied moment and corresponding rotation could be recorded.

- Cyclic tests [C]: This allowed the serviceability behaviour to be assessed under a representative loading regime (a large static wind force augmented by a varying wind and wave load). This loading was approximated by a sine wave with variable static and dynamic components. The load orientation and magnitude are characterised by the formulations of LeBlanc et al., (2010b) as follows:

$$
\begin{aligned}
& \xi_{b}=\frac{M_{\max }}{M_{R}} \\
& 1 \\
& \xi_{c}=\frac{M_{\text {min }}}{M_{\max }}
\end{aligned}
$$

Where $\xi_{b}$ defines is the load level and $\xi_{c}$ defines the load directionality $\left(\xi_{c}=-1\right.$ represents a symmetrical two-way loading and $\xi_{c}=0$ represents a purely one-way regime).

\section{Analysis}

Throughout the test the horizontal displacement and load were recorded. Knowing the loading height and lateral displacement, the moment applied and the angular rotation of the caisson could be assessed. Using this moment rotation data it was possible to calculate the unloading rotational stiffness of the caisson system by identifying the maximum and minimum loads and their corresponding rotations within each loading cycle. This methodology is identical to that used by LeBlanc et al., (2010a) and is illustrated in Figure 13. 


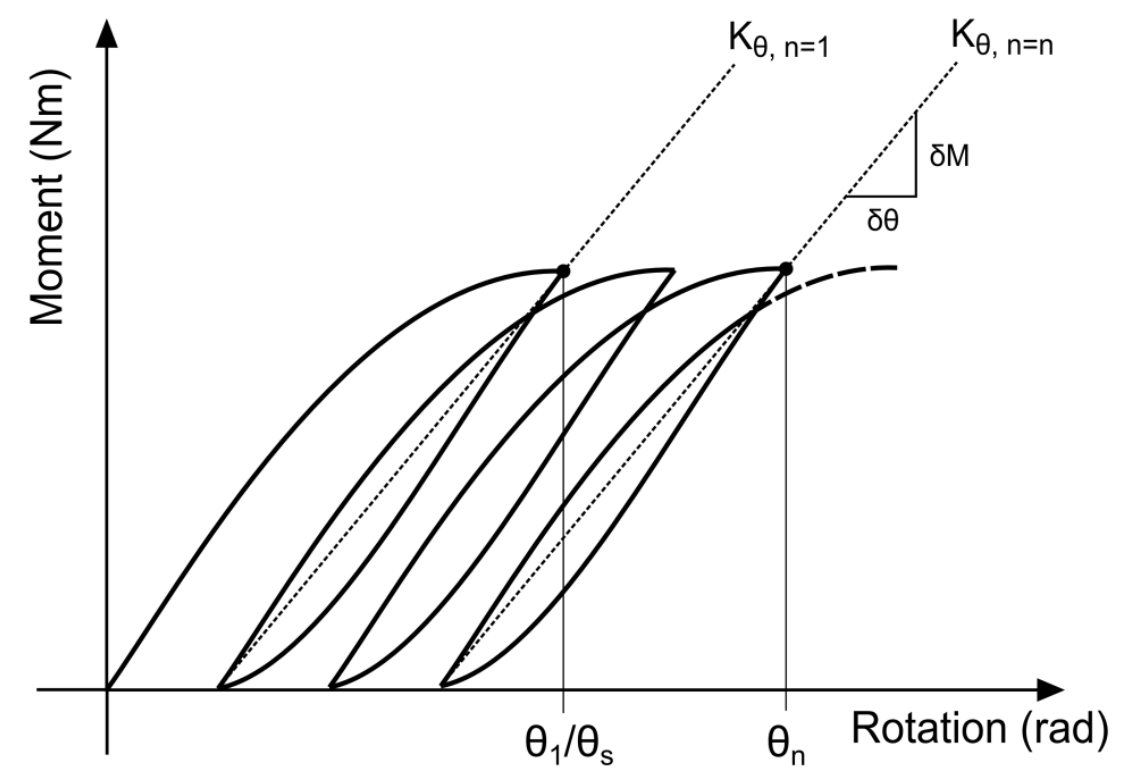

Figure 3: Assessment of rotational stiffness and accumulation of rotation after Cox, (2014).

The accumulation of structural rotation was assessed by considering the median rotation (average of the maximum and minimum rotations) during each loading cycle. This change in rotation was then normalised with respect to the static rotation amplitude $\theta_{s}$, (the rotation observed when the peak moment load is applied to the foundation under a static loading condition), this is illustrated in Figure 13.

\section{Experimental Results}

As part of this investigation, a total of 39 tests were conducted. The non-dimensionalised properties of the test series are summarised in Table 4.

\subsection{Push over}

All push over tests were conducted at a representative loading height ( $M / H D \approx 5-6)$ and loaded at a constant rate. The observed moment rotation response for all of the caissons considered can be seen in Figure 14. From Figure 14 a number of things can be inferred about the behaviour of a suction caisson system. The B2 caissons exhibit a more ductile response than the B3 caissons. Where the B3 caissons display a brittle failure mechanism with a residual load similar to that of the peak load (Kourkoulis et al., 2014), the B2 models continues to gain strength well beyond the apparent elastic limit. This ductile behaviour can be attributed to the increased embedment/reduced aspect ratio of the caisson. The yield load for each caisson is summarised in Table 5, evaluated using the same methodology as Zhu et al., (2013). 


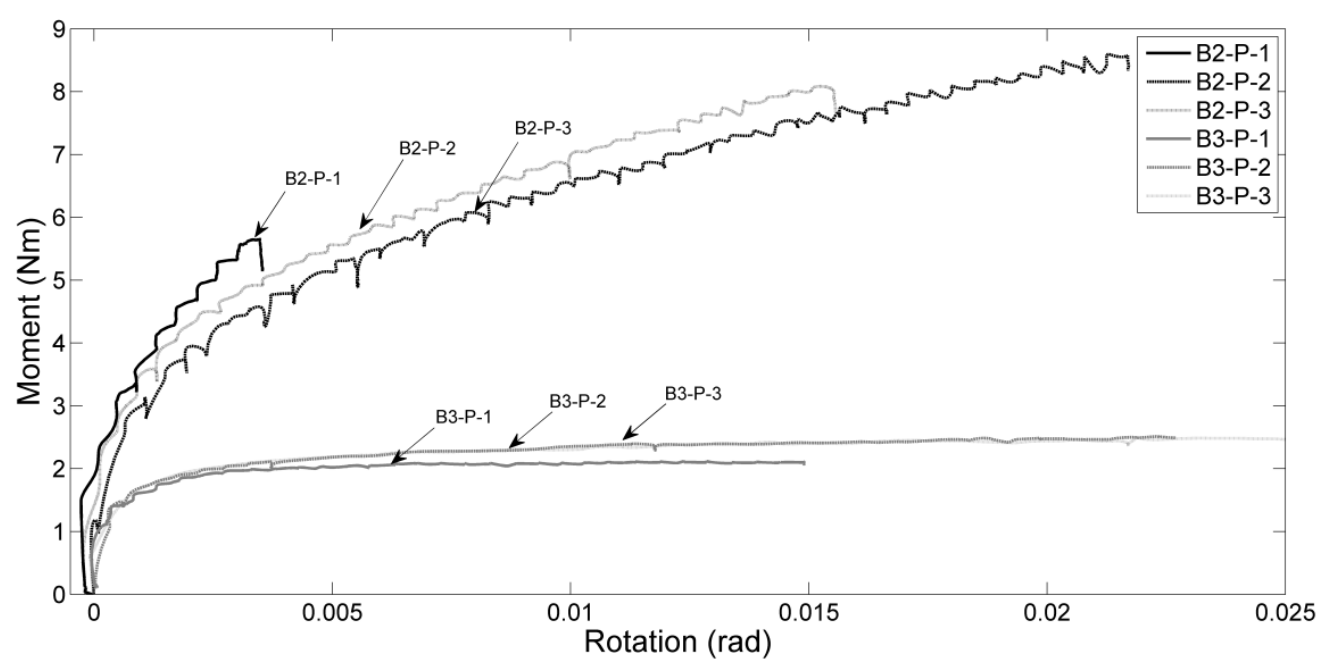

Figure 4: Caisson moment rotation plots a) 1:100 tests

\subsection{Unloading stiffness}

Using the cyclic tests conducted within this investigation, the change in foundation stiffness with number of loading cycles for the B2 and B3 caissons could be assessed. Selected results for the B2 and B3 caissons are illustrated in Figure 15.

From Figure 15 it can be seen that the caisson stiffness is somewhat erratic (due to the low rotation levels), but shows a consistent stiffening response with increasing number of cycles. The evolution of foundation stiffness under a periodic loading has been considered by a number of authors. Analogous work conducted by Sawicki and Swidzinski, (1989) on the stiffness of a sand element under tri-axial loading conditions and by Li et al., (2010) on the stiffness of a model pile system have both used a logarithmic relationship to describe the change in foundation stiffness with number of loading cycles. Using the same logarithmic relationship, the observed changes in non-dimensional stiffness with increasing number of loading cycles could be described by the following equation:

$\tilde{k}=K_{0}+A_{k} \ln (N)$

3

Where $\tilde{k}$ is the instantaneous non-dimensional foundation stiffness, $K_{0}$ is the characteristic nondimensional foundation stiffness and $A_{k}$ is the stiffness change parameter. Using a least squares fitting methodology it was possible to provide an estimation as to the stiffness coefficients, these are summarised in Table 6.

From inspection the stiffness appears to be dependent on the rotational amplitude. In previous investigations the transient stiffness behaviour has been equated to the load level $\left(\xi_{b}\right)$ and load directionality $\left(\xi_{c}\right)$ (LeBlanc et al., 2010a), however it may be more appropriate to evaluate the caisson behaviour in terms of the rotation amplitude $(\Delta \theta)$ applied to the foundation during the first loading cycle (Cox et al., 2015). Considering the non-dimensionalised push over results, it was possible to compare the push over stiffness to the characteristic caisson stiffness $\left(\mathrm{K}_{0}\right)$ at the same rotational strain. This is illustrated in Figure 16.

From Figure 16 it can be seen that there is a good agreement between the non-dimensional stiffness obtained during a push over tests and that of the estimated characteristic caisson stiffness $\left(K_{0}\right)$. The push over response appears to provide a reasonable prediction as to the characteristic stiffness of the caisson system. 
Considering the two stiffness parameters further it is evident that the lower the foundation stiffness $\left(\mathrm{K}_{0}\right)$ the greater the stiffness change parameter $\left(\mathrm{A}_{\mathrm{k}}\right)$. This is illustrated in Figure 17 comparing the foundation stiffness and the stiffness change parameter.
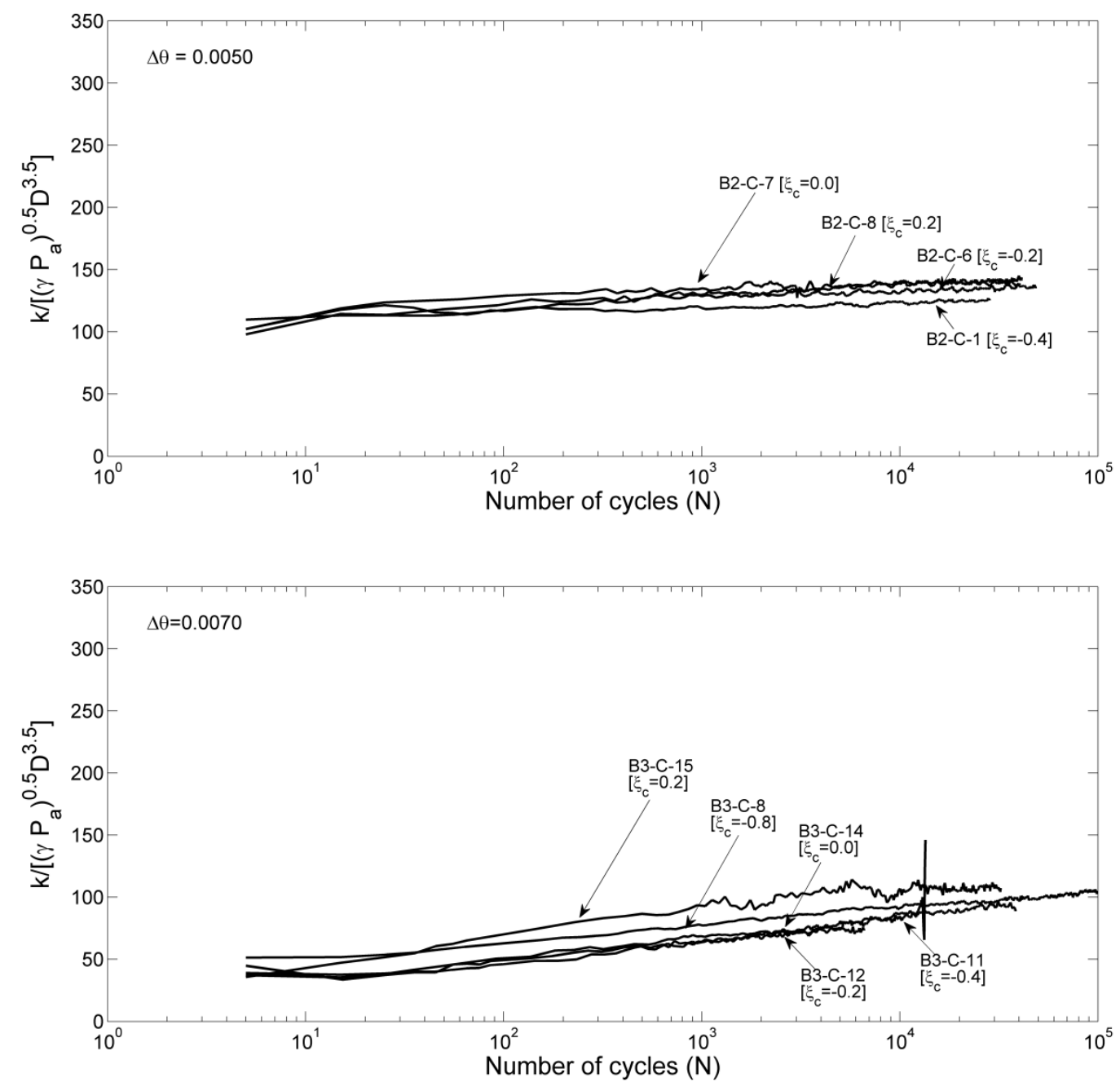

Figure 5: Change of caisson stiffness with increasing cycles.

Such a correlation is expected as a lower characteristic stiffness corresponds to a higher starting void ratio, typically when a cyclic load is applied to a loose sand it will show some densification behaviour. The higher the initial void ratio the greater the potential for the sand sample to densify and the higher the rate of stiffness change $\left(A_{k}\right)$ observed. Similar behaviour was noted by Klinkvort and Hededal, (2013) in tests on monopiles. 


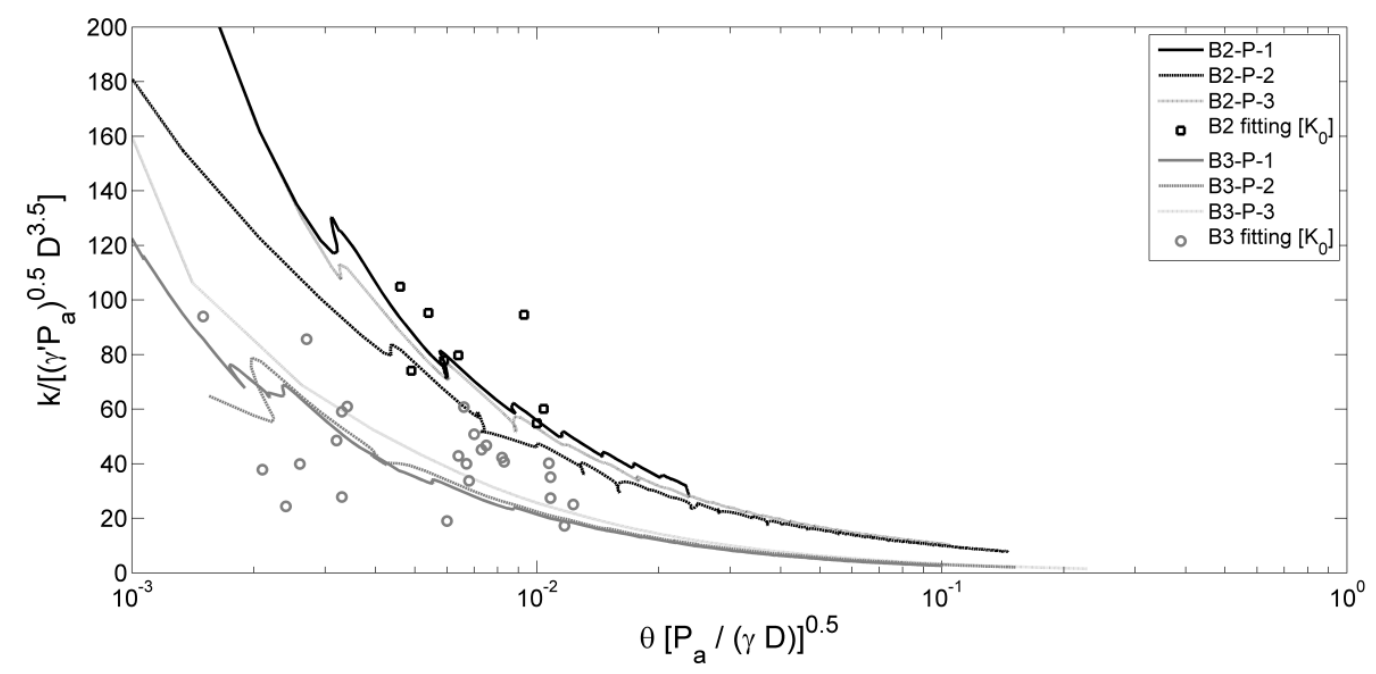

Figure 6: Characteristic caisson stiffness parameter $\left(\mathrm{K}_{0}\right)$ for the B2 and B3 caissons.

\subsection{Rotation of the caisson}

Using the cyclic test results conducted within this investigation the accumulation of structural rotation could be assessed. Selected results showing the accumulation of rotation for the B2 and B3 caissons can be seen in Figure 18.

In all cases an initial rapid accumulation of rotation was observed which slowed with additional loading cycles (and increased foundation stiffness). Similar behaviour was observed in analogous experiments by Lin and Liao, (1999), Verdure et al., (2003) and Li et al., (2010) who proposed a logarithmic relationship to describe the response of a cyclically loaded monopile foundation. Alternatively a power relationship was used by Long and Vanneste, (1994), LeBlanc et al., (2010a) and Klinkvort et al., (2010) for monopiles, and by Zhu et al., (2013) and Foglia et al., (2014) for caissons. From preliminary analysis it was found that the power relationship best described the observed behaviour. As such the longterm prediction of rotation accumulation took the following form:

$\frac{\Delta \theta(N)}{\theta_{s}}=T . N^{\alpha}$

Where $\Delta \theta(N)$ is the accumulated rotation, $\theta_{S}$ is the static rotation, $T$ is the rotation coefficient and $\alpha$ is the rotation accumulation exponent. Using a least squares fitting methodology it was possible to provide an estimation as to the accumulation of structural rotation observed under cyclic loading. From analysis it was found that a rotation accumulation exponent of 0.3 best fitted the observed data. Accordingly the fitting exponents are summarised in Table 6.

Within other investigations the accumulation of rotation was described in-terms of the relative load level $\left(\xi_{b}\right)$ and load directionality $\left(\xi_{c}\right)$ (LeBlanc et al., 2010a, Zhu et al., 2013 and Foglia et al., 2014). From the behaviour seen within this investigation there appears to be no clear trend between the relative load level $\left(\xi_{b}\right)$ and the accumulation of structural rotation. As the non-dimensional rotation amplitude $(\Delta \tilde{\theta})$ provides a better appreciation as to the soil strain than the load level $\left(\zeta_{b}\right)$, the accumulation of rotation was assessed considering rotation amplitude $(\Delta \tilde{\theta})$. The rotation coefficient $T$ can therefore be evaluated as the product of two components, the rotation amplitude $\left(T_{\theta}\right)$, and the load directionality $\left(T_{c}\right)$. This is summarised as follows:

$\frac{\Delta \theta(N)}{\theta_{s}}=T_{c} \cdot T_{\theta} \cdot N^{\alpha}$

5 
Selecting and identifying tests conducted at the same rotation amplitude $(\Delta \tilde{\theta})$ and at the same loading orientation $\left(\xi_{c}\right)$, the influence of each loading component could be assessed individually. The effect of loading direction on the accumulation of rotation $\left(T_{c}\right)$ can be seen in Figure 19 and the effect of the non-dimensional rotation amplitude $(\Delta \tilde{\theta})$ on the accumulation of rotation can be seen in Figure 20 .

From Figure 19 the effect of load orientation on the accumulation of rotation matches well with the observations LeBlanc et al., (2010a). Further from Figure 20, the greater the non-dimensional rotation amplitude applied, the greater the accumulation of structural rotation.

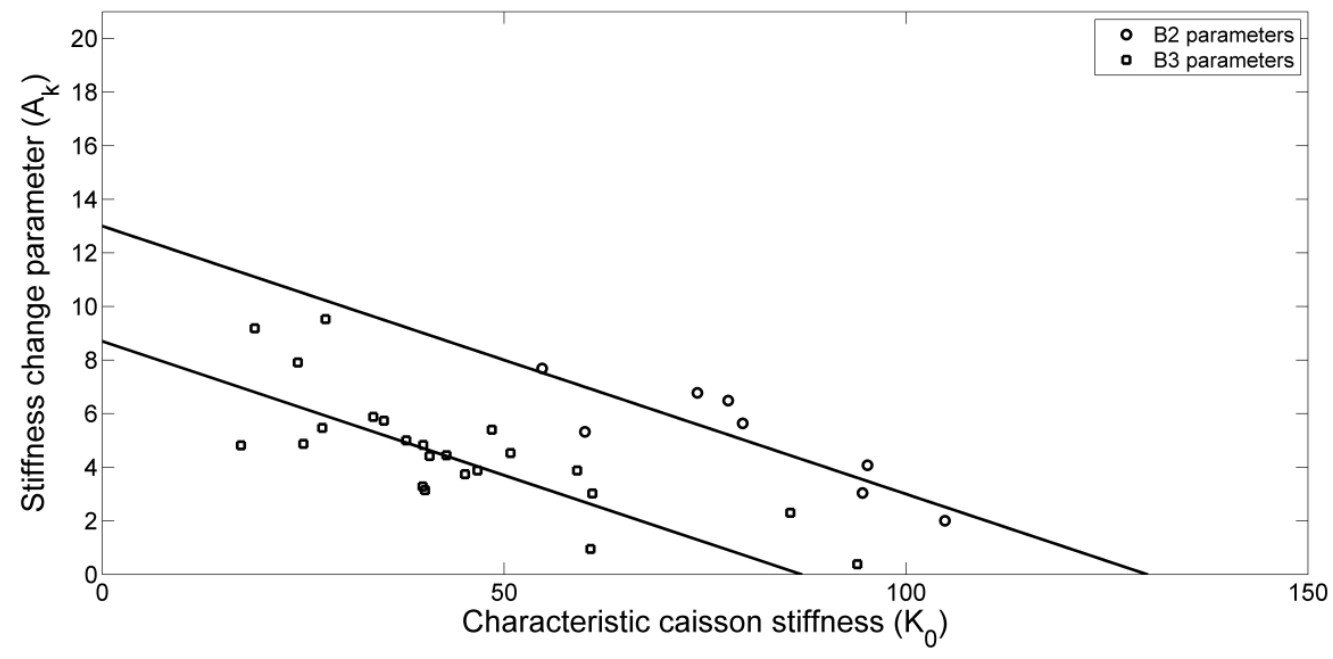

Figure 7: Relation between non-dimensional $K_{0}$ and $A_{k}$ values 

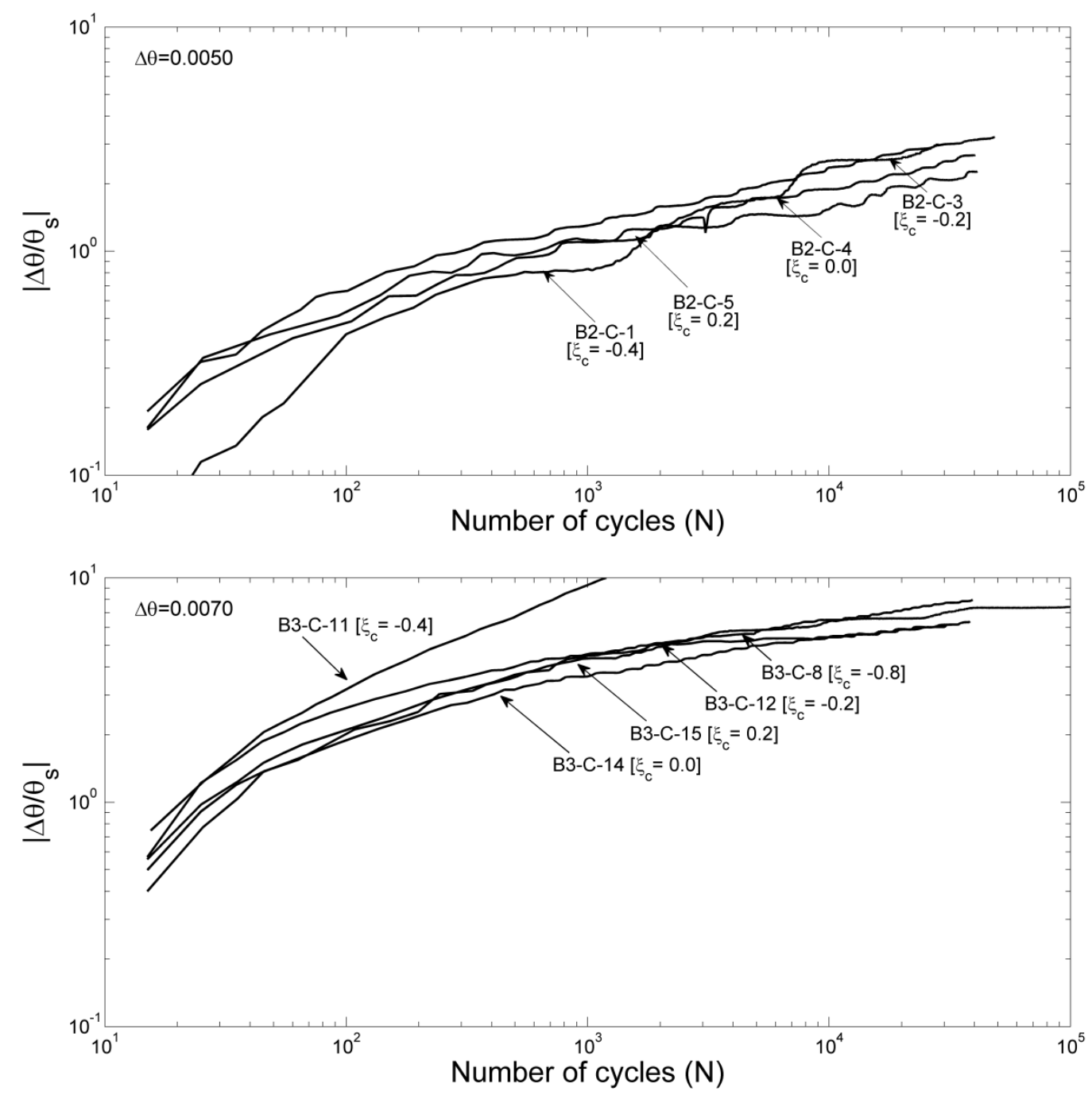

Figure 8: Accumulation of structural rotation with loading cycles for the (a) B2 and (b) B3 caissons. 


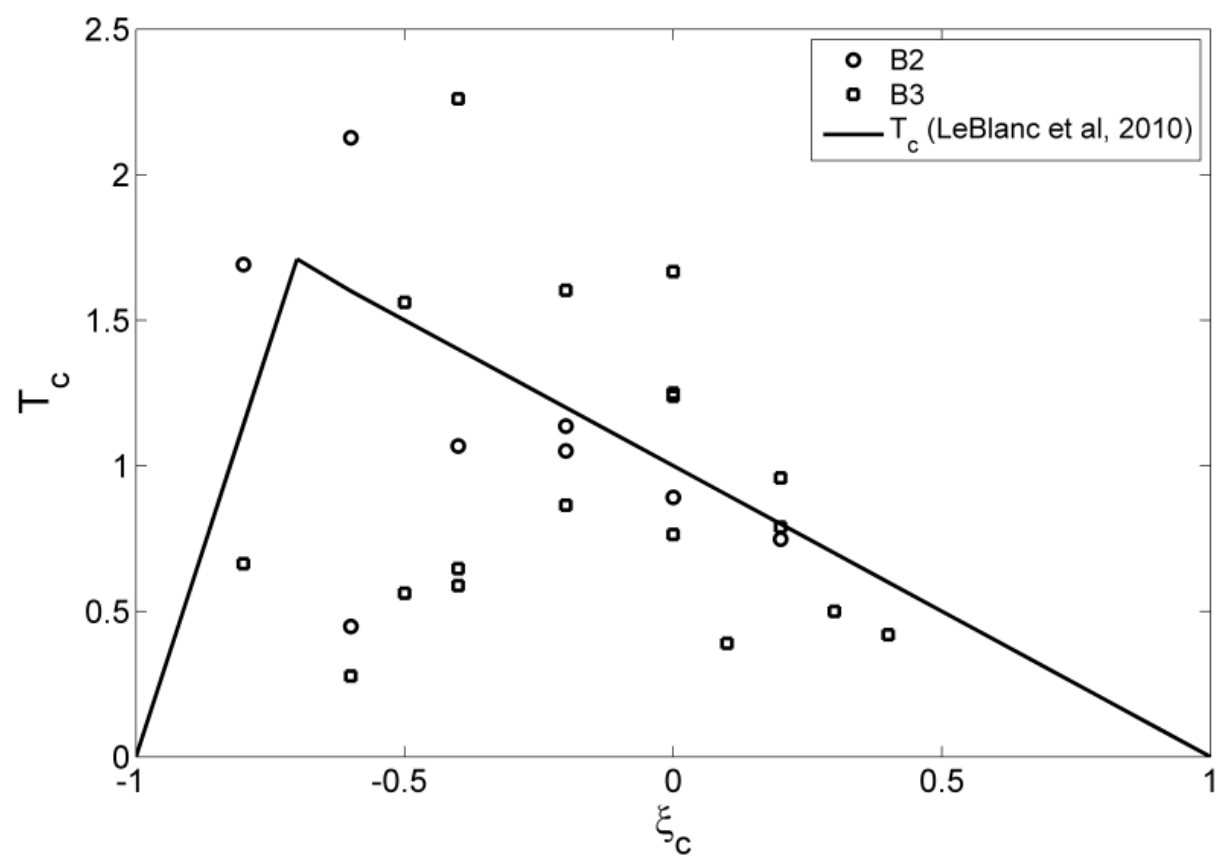

Figure 9: Effect of loading direction on the accumulation of rotation

\section{Comparison to other data sets}

Considering the behaviour observed in these tests it's possible to compare the results to similar investigations conducted on the cycle dependant serviceability of other foundations. It was found that a stiffness change parameter $\left(A_{k}\right)$ in the range of $0-30$ characterised the data observed within this investigation, this compares well to an average parameter of 8.02 obtained for piles by LeBlanc et al., (2010a). In the investigation by Zhu et al., (2013) on suction caissons, no assessment of the changing stiffness was undertaken as the magnitudes observed were minimal.

A rotation accumulation exponent of $\alpha=0.3$ was found to best represent the data. A similar exponent value of $\alpha=0.31$ was reported by LeBlanc et al., (2010a) and $\alpha=0.13$ by Nicolai and Ibsen, (2014), for monopiles subjected to a series of cyclic loading regimens. In addition both Zhu et al. (2013) and Foglia et al. (2014) conducted cyclic load tests on caisson foundations, Zhu et al., (2013) reported a rotation coefficient of $\alpha=0.39$ for caissons in dry sand and Foglia et al., (2014) identified an exponent of $\alpha=$ 0.18 for caissons in saturated sand. This comparative difference in the rotation coefficients is likely an effect of differential sand properties and the flexibility of the caisson. 


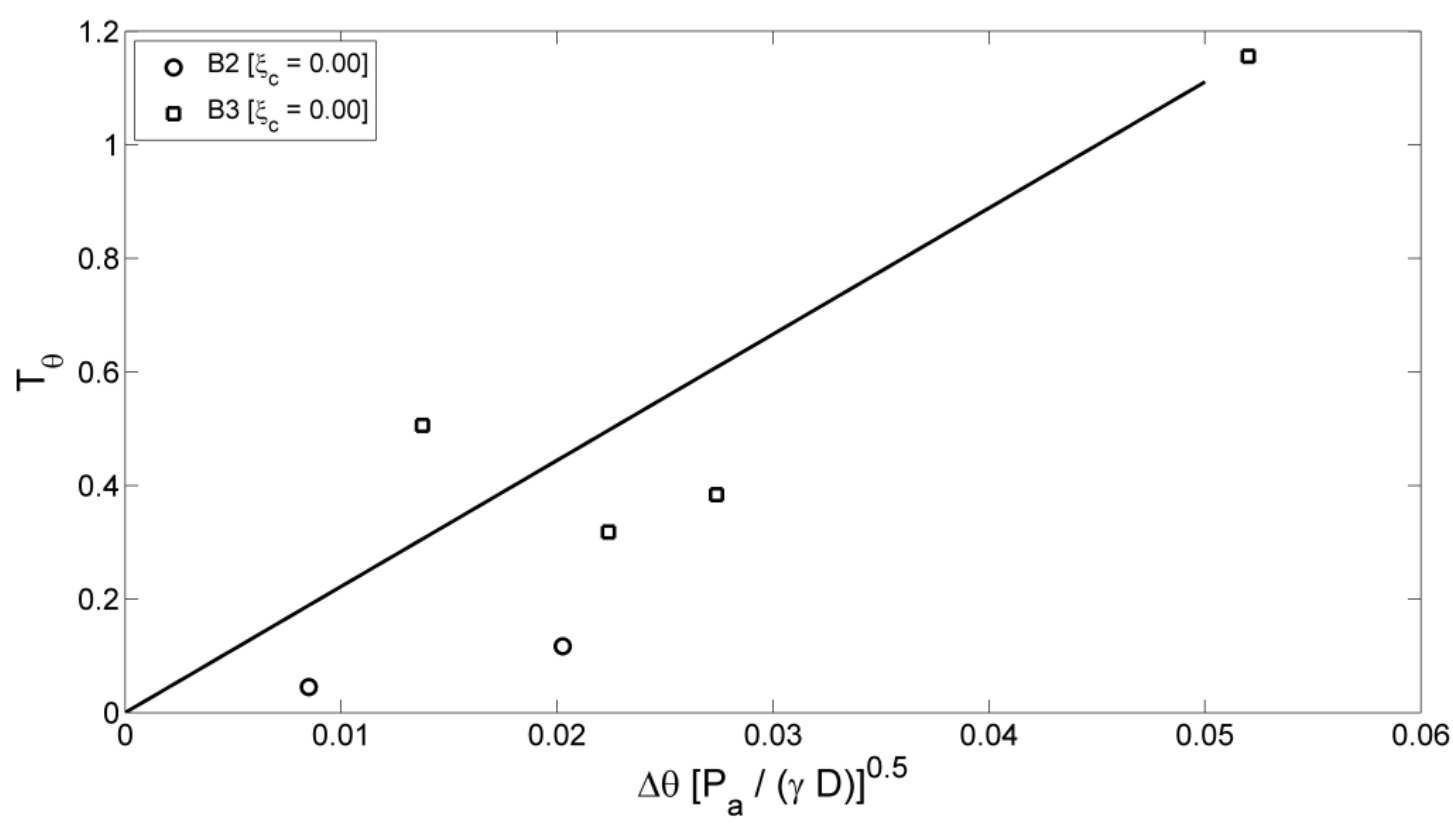

Figure 10: Effect of non-dimensional rotation amplitude $(\Delta \tilde{\theta})$ on the accumulation of rotation

\section{Conclusion}

From the data presented within this paper a number of observations concerning the serviceability behaviour of a suction caisson system can be made. Tests of up to 170,000 cycles were applied to the model system with the aim of investigating the long-term behaviour, this is short of the $1 \times 10^{8}$ cycles that may potentially be applied to a structure over a 20 year lifetime. Despite this, the obtained results have illustrated a number of clear trends and behaviours:

a) The aspect ratio of the caisson has a significant effect on the foundation stiffness, with a stiffer and more ductile response exhibited by those with a higher aspect ratio.

b) The rotational stiffness of the caisson system increased when subjected to a repetitive cyclic loading. The rate of foundation stiffness change $\left(A_{k}\right)$, corresponded with the characteristic non-dimensional foundation stiffness $\left(\mathrm{K}_{0}\right)$ observed during the first loading cycle. The foundation stiffness $\left(\mathrm{K}_{0}\right)$ was found to be dependent on the rotation amplitude $(\Delta \tilde{\theta})$ and was well predicted from the non-dimensionalised push-over test results.

c) Under cyclic loading a suction caisson will accumulate permeant rotation under a fully drained condition. This rotation was dependent on the rotation amplitude $(\Delta \tilde{\theta})$ and relative directionality of the loading $\left(\xi_{c}\right)$. In general a cyclic regime between one-way and two-way loading caused the greatest accumulation of rotation, such behaviour is similar to observations made by other authors. 


\section{List of Tables}

Table 1: Prototype non-dimensional groupings.

Table 2: Non-dimensional system behaviour Kelly et al., (2006)

Table 3: Properties of Leighton Buzzard Fraction B sand (Stroud, 1971; Cai, 2010)

Table 4: Scale model non-dimensional parameters.

Table 5: Experimental caisson yield load.

Table 6: Caisson serviceability behaviour under cyclic loading. 


\section{Figure captions}

Figure 11: Typical cyclic loads and dynamically sensitive regions of a NREL 5MW turbine structure (Cox et al., 2015).

Figure 12: Schematic of the cyclic loading apparatus after Cox, (2014).

Figure 13: Assessment of rotational stiffness and accumulation of rotation after Cox, (2014).

Figure 14: Caisson moment rotation plots under an increasing load.

Figure 15: Selected tests showing the change of caisson stiffness with increasing cycles for the (a) B2 and (b) B3 caissons.

Figure 16: Characteristic caisson stiffness parameter $\left(\mathrm{K}_{0}\right)$ for the $\mathrm{B} 2$ and $\mathrm{B} 3$ caissons.

Figure 17: Relation between non-dimensional $K_{0}$ and $A_{k}$ values.

Figure 18: Accumulation of structural rotation with loading cycles for the (a) B2 and (b) B3 caissons.

Figure 19: Effect of loading direction on the accumulation of rotation.

Figure 20: Effect of non-dimensional rotation amplitude $(\Delta \tilde{\theta})$ on the accumulation of rotation. 
References

ANDERSEN, K. H., MURFF, J. D., RANDOLPH, M. F., CLUKEY, E., ERBRICH, C. T., JOSTAD, H. P., HANSEN, J. B., AUBENY, C., SHARMA, P. \& SUPACHAWAROTE, C. 2005. Suction anchors for deepwater applications. In: GOURVENEC, S. \& CASSIDY, M. J. (eds.) Frontiers in Offshore Geotechnics: ISFOG. Perth, WA: Taylor \& Francis Group.

BHATTACHARYA, S., COX, J. A., LOMBARDI, D. \& MUIR WOOD, D. 2012. Dynamics of offshore wind turbines on two types of foundations. Proceedings of the Institution of Civil Engineers: Geotechnical Engineering, 166.(2), $159-169$.

BYRNE, B. W. 2000. Investigations of Suction Caissons in Dense Sand. Doctor of Philosophy, University of Oxford.

CAI, Y. 2010. An Experimental Study of Non-Coaxial Soil Behaviour Using Hollow Cylinder Testing. Doctor of Philosophy, University of Nottingham.

CARTER, J. M. F. 2007. North Hoyle offshore wind farm: design and build. Proceedings of the Institution of Civil Engineers: Energy, 160.(1), 21 - 29.

COX, J. A. 2014. Long-Term Serviceability Behaviour of Suction Caisson Supported Offshore Wind Turbines. PhD, University of Bristol

COX, J. A., O'LOUGHLIN, C., CASSIDY, M. J., BHATTACHARYA, S., GAUDIN, C. \& BIENEN, B. 2015. Centrifuge Study on the Cyclic Performance of Caissons in Sand. Submitted for publication in the International Journal of Physical Modelling in Geotechnics.

DET NORSKE VERITAS 2002. Guidelines for Design of Wind Turbines. In: DET-NORSKE-VERITAS (ed.). Copenhagen, Denmark.

DET NORSKE VERITAS 2010. Buckling Strength of Shells DNV-OS-C202. Norway.

DOHERTY, J. P. \& DEEKS, A. J. 2003. Elastic response of circular footings embedded in a nonhomogeneous half-space. Geotechnique, 53.(8), 703 - 714.

DOHERTY, J. P., HOULSBY, G. T. \& DEEKS, A. J. 2005. Stiffness of Flexible Caisson Foundations Embedded in Nonhomogeneous Elastic Soil. Journal of Geotechnical and Geoenvironmental Engineering, 131.(12), 1498 - 1508.

DTI 2007. Study of the Costs of Offshore Wind Generation. A Report to the Renewables Advisory Board \& DTI.

EUROPEAN WIND ENERGY ASSOCIATION 2016. The European offshore wind industry - key trends and statistics 2013. Brussels, Belgium.

FELD, T. 2001. Suction Buckets, a New Innovative Foundation Concept, Applied to Offshore Wind Turbines. PhD Thesis, Aalborg University.

FOGLIA, A., IBSEN, L. B., NICOLAI, G. \& ANDERSEN, L. V. 2014. Observations on bucket foundations under cyclic loading in dense saturated sand. In: GAUDIN, C. \& WHITE, D. (eds.) ICPMG2014 Physical Modelling in Geotechnics: Proceedings of the 8th International Conference on Physical Modelling in Geotechnics Perth, Australia: CRC Press.

GAUDIN, C., CLUKEY, E., GARNIER, J. \& PHILLIPS, R. 2010. New frontiers for centrifuge modelling in offshore geotechnics. Frontiers in Offshore Geotechnics II. CRC Press.

HARDIN, B. O. \& DRNEVICH, V. P. 1972. Shear Modulus and Damping in Soils: Design equations and curves. Journal of the Soil Mechanics and Foundations Division, ASCE, 98.(7), 667-692.

HOADLEY, P. J., BARTON, Y. O. \& PARRY, R. H. G. 1981. Cyclic lateral load on model pile in a centrifuge. Proceedings of the Tenth International Conference on Soil Mechanics and Foundation Engineering. Stockholm, Sweden: Balkema.

HOULSBY, G. T., IBSEN, L. B. \& BYRNE, B. W. 2005. Suction caissons for wind turbines. In: CASSIDY, G. (ed.) Frontiers in Offshore Geotechnics: ISFOG. Perth, Australia: Taylor \& Francis Group, London.

KELLY, R. B., HOULSBY, G. T. \& BYRNE, B. W. 2006. A comparison of field and laboratory tests of caisson foundations in sand and clay. Géotechnique, 56.(9), 9. 
KLINKVORT, R. T. \& HEDEDAL, O. 2013. Lateral response of monopile supporting an offshore wind turbine. Proceedings of the ICE - Geotechnical Engineering [Online], 166. Available: http://www.icevirtuallibrary.com/content/article/10.1680/geng.12.00033.

KLINKVORT, R. T., LETH, C. T. \& HEDEDAL, O. 2010. Centrifuge modelling of a laterally cyclic loaded pile. Physical Modelling in Geotechnics. Taylor \& Francis.

KOURKOULIS, R. S., LEKKAKIS, P. C., GELAGOTI, F. M. \& KAYNIA, A. M. 2014. Suction caisson foundations for offshore wind turbines subjected to wave and earthquake loading: effect of soil-foundation interface. Géotechnique, 64.(3), 171-185.

LARSEN, J. H. M., SOERENSEN, H. C., CHRISTIANSEN, E., NAEF, S. \& VøLUND, P. 2005. Experiences from Middelgrunden $40 \mathrm{MW}$ Offshore Wind Farm. Copenhagen Offshore Wind. Copenhagen.

LEBLANC, C. 2009a. Design of Offshore Wind Turbine Support Structures. Doctor of Philosophy, Technical University of Denmark.

LEBLANC, C. 2009b. The Monopod Bucket Foundation : Recent experiences and challenges ahead. Hamburg Offshore Wind Conference 2009. Hamburg: GL Group.

LEBLANC, C., HOULSBY, G. T. \& BYRNE, B. W. 2010a. Response of stiff piles in sand to long-term cyclic lateral loading. Géotechnique, 60.(2), 11.

LEBLANC, C., HOULSBY, G. T. \& BYRNE, B. W. 2010b. Response of stiff piles to random two-way lateral loading. Géotechnique, 60.(9), 6.

LI, Z., HAIGH, S. K. \& BOLTON, M. D. 2010. Centrifuge modelling of mono-pile under cyclic lateral loads. 7th International Conference on Physical Modelling in Geotechnics. Zurich.

LIINGAARD, M. A. 2006. Dynamic Behaviour of Suction Caissons. Doctor of Philosophy, Technical University of Denmark,.

LIN, S. \& LIAO, J. 1999. Permanent Strains of Piles in Sand due to Cyclic Lateral Loads. Journal of Geotechnical and Geoenvironmental Engineering, 125.(9), 798-802.

LONG, J. \& VANNESTE, G. 1994. Effects of Cyclic Lateral Loads on Piles in Sand. Journal of Geotechnical Engineering, 120.(1), 225-244.

MOCCIA., F. 2009. Seismic Soil Pile Interaction: Experimental Evidence. Doctor of Philosophy, Università degli Studi di Napoli Federico II.

NICOLAI, G. \& IBSEN, L. B. Small-scale testing of cyclic laterally loaded monopiles in dense saturated sand. The Twenty-fourth International Ocean and Polar Engineering Conference, 2014. International Society of Offshore and Polar Engineers.

PEIRE, K., NONNEMAN, H. \& BOSSCHEM, E. 2009. Gravity based foundations for the Thornton Bank Offshore Wind Farm. Terra et Aqua, 115.(19 - 29.

RANDOLPH, M. F. \& WROTH, C. P. 1979. An analytical solution for the consolidation around a driven pile. International Journal for Numerical and Analytical Methods in Geomechanics, 3.(3), 217229.

SAWICKI, A. \& SWIDZINSKI, W. 1989. Mechanics of a Sandy Subsoil Subjected to Cyclic Loadings. International Journal for Numerical and Analytical Methods in Geomechanics, 13.(5), 19.

STROUD, M. A. 1971. The Behaviour of Sand at Low Stress Levels in the Simple Shear Shear Apparatus. Doctor of Philosophy, Cambridge University,.

TRAN, M. N. 2005. Installation of Suction Caissons in Dense Sand and the Influence of Silt and Cemented Layers. Doctor of Philosophy, The University of Sydney.

VERDURE, L., GARNIER, J. \& LEVACHER, G. 2003. Lateral Cyclic Loading of Single Piles in Sand. International Journal of Physical Modelling in Geotechnics, 3.(3), 17-28.

VILLALOBOS, F. A. 2006. Model Testing of Foundations for Offshore Wind Turbines. Doctor of Philosophy, University of Oxford.

ZAAIJER, M. B. 2009. Review of Knowledge Development for the Design of Offshore Wind Energy Technology. Wind Energy, 12.(5), 411 - 430.

ZHANG, P., DING, H. \& LE, C. 2014. Seismic response of large-scale prestressed concrete bucket foundation for offshore wind turbines. Journal of Renewable and Sustainable Energy, 6.(1), 013127. 
ZHU, B., BYRNE, B. \& HOULSBY, G. T. 2013. Long-Term Lateral Cyclic Response of Suction Caisson Foundations in Sand. Journal of Geotechnical and Geoenvironmental Engineering, 139.(1), 7383. 